\title{
Fibroblasts associated with cancer cells keep enhanced migration activity after separation from cancer cells: A novel character of tumor educated fibroblasts
}

\author{
GENICHIRO ISHII $^{1}$, HIROKO HASHIMOTO ${ }^{1}$, KIYOSHI ASADA ${ }^{2}$, TAKASHI ITO ${ }^{1,3}$, AYUKO HOSHINO ${ }^{1,3}$, \\ SATOSHI FUJII ${ }^{1}$, MOTOHIRO KOJIMA ${ }^{1}$, TAKESHI KUWATA ${ }^{1}$, KENICHI HARIGAYA ${ }^{4}$, \\ KANJI NAGAI ${ }^{5}$, TOSHIKAZU USHIJIMA ${ }^{2}$ and ATSUSHI OCHIAI ${ }^{1,3}$ \\ ${ }^{1}$ Pathology Division, Research Center for Innovative Oncology, National Cancer Center Hospital East, Kashiwa, Chiba; \\ ${ }^{2}$ Carcinogenesis Division, National Cancer Center Research Institute, Tokyo; ${ }^{3}$ Laboratory of Cancer Biology, \\ Department of Integrated Biosciences, Graduate School of Frontier Sciences, The University of Tokyo, \\ Kashiwa, Chiba; ${ }^{4}$ Molecular and Tumor Pathology, Graduate School of Medicine, Chiba University; \\ ${ }^{5}$ Thoracic Oncology Divisions, National Cancer Center Hospital East, Kashiwa, Chiba, Japan
}

Received February 12, 2010; Accepted April 29, 2010

DOI: 10.3892/ijo_00000680

\begin{abstract}
It is now clear that the association between cancer cells and recruited fibroblasts (cancer-associated fibroblasts; CAFs) leads to alteration of the biological properties of both types of cells and creates a specific microenvironment. Here we report a novel biological property of CAFs and its cellular mechanism using in vivo and in vitro model. Cultured CAFs derived from human lung cancer tissue displayed significantly higher migration activity in response to PDGF-BB than that of fibroblasts from corresponding non-cancerous tissue (NCAFs). Moreover, KM104 ${ }^{\mathrm{GFP}}$ (GFP-labeled human fibroblast cell line) co-cultured with human cancer cell line Capan-1 showed significantly higher migration activity than KM104GFP alone. No such phenomenon occurred when KM104GFP and Capan-1 were cultured separately. Even after KM104GFP were sorted from co-cultured Capan-1, KM104 ${ }^{\mathrm{GFP}}$ retained their enhanced migration activity until passage- 5 of culture in the absence of cancer cells. Despite a similar level of phosphorylation of ERK1/2 after exposure to PDGF-BB, the inhibitory effect of MEK inhibitor was significantly higher on migration of KM104 ${ }^{\mathrm{GFP}}$ that had been sorted from co-cultured Capan-1 than of KM104GFP alone. This higher dependence on ERK1/2 signaling for cell migration was also seen in CAFs obtained from cancer tissue. The results of this study indicate that by association with cancer cells, CAFs can acquire enhanced migration activity which could be kept after separation from
\end{abstract}

Correspondence to: Dr Genichiro Ishii or Dr Atsushi Ochiai, Pathology Division, Research Center for Innovative Oncology, 6-5-1 Kashiwanoha, Kashiwa, Chiba 277-8577, Japan

E-mail: gishii@east.ncc.go.jp;

E-mail: aochiai@east.ncc.go.jp

Key words: cancer associated fibroblast, MAP kinase, migration activity cancer cells and suggest the possibility that higher dependence on ERK1/2 signaling for enhanced migration activity would be one of the biological properties of CAFs.

\section{Introduction}

During the process of cancer cell invasion, the cancer cells associate with several types of stromal cells that together create the specific microenvironment of the cancer tissue. It is becoming clear that the microenvironment plays an important role in allowing the tumor to express its full neoplastic phenotype $(1,2)$. Fibroblasts, which are the major component of the newly created stroma, are recruited from neighboring tissues and remote organs (3-7). This recruitment step is called the 'desmoplastic reaction' and is a kinetic sequence of events in the invasion process. Within the cancer tissue, the fibroblasts directly communicate with the cancer cells and other types of stromal cells and acquire a specific biological phenotype $(8,9)$. The type of fibroblast in cancer tissue that has acquired a specific biological phenotype is called cancer-associated fibroblast (CAF), and such fibroblasts have been postulated to perform supportive roles that promote tumor progression and metastasis by secreting growth factors $(10,11)$, chemokines $(12,13)$, and matrix metalloproteinases (MMPs) $(14,15)$. Although an increasing number of translational studies have emphasized the prognostic significance of the altered phenotype of CAFs (16-18), the cellular mechanisms of these alterations remain unclear.

It is noteworthy that expression of specific molecules on CAFs is maintained under in vitro conditions, which means that alterations of gene expression in CAFs are capable of being stably maintained even in the absence of continued exposure to cancer cells. Actually, in a comparison with cultured non-cancerous fibroblasts Nakagawa et al found that approximately 170 of 22,000 genes were up-regulated in cultured CAFs (fold change $>2, \mathrm{P}<0.05$ ), and that the upregulated genes included many genes that encode cell 
adhesion molecules and growth factors (19). However, the mechanisms by which specific gene expression is induced in $\mathrm{CAF}$ are controversial. In some studies, the frequency of $\mathrm{LOH}$ in CAFs has been reported to be similar to the frequency observed in the epithelial components (20-22). Qiu et al, on the other hand, reported that $\mathrm{LOH}$ and copy number alterations were extremely rare in CAFs from breast and ovarian cancers (23). Very little is known as to how genetic or epigenetic status can modify gene expression and cellular signaling(s) in CAFs.

The desmoplastic reaction during cancer progression centers on various functions of fibroblasts (24). One of the representative phenotypes involved in this reaction is migration activity, which is thought to be related to cancer progression (25). In this study we used in vivo and in vitro models to investigate the biological characteristics of CAFs, with a special focus on their migration activity and the cellular mechanism.

\section{Materials and methods}

Human fibroblast culture. Cancer-associated fibroblasts (CAFs) and non-cancerous tissue-associated fibroblasts (NCAFs) were obtained from the surgically resected lungs of lung cancer patients as previously reported (26). Briefly, approximately $5-\mathrm{mm}^{3}$ carcinoma tissue and non-cancerous lung tissue specimens were cut into about ten pieces and each was placed in $\alpha$-MEM (Gibco, Grand Island, NY) culture medium with $10 \%$ heat-inactivated FBS and antibiotics (penicillin and streptomycin) (Sigma, St. Louis, MO). The medium was changed every other day until the tissue was surrounded by adherent fibroblasts. The tissue was then removed and cultured for two more days. When the cells reached $80 \%$ confluence they were harvested with $0.25 \%$ trypsin and $1 \mathrm{mmol} / \mathrm{l}$ EDTA and then replated at a density of $1 \times 10^{4}$ cells $/ \mathrm{cm}^{2}$. The fibroblasts were separated from contaminating epithelial and macrophages by differential trypsinization and used between passages 3 and 7. All specimens were collected after the subjects had given their written informed consent and it was approved by the Institutional Review Board of the National Cancer Center.

Animals. Six-week-old female severe combined immunodeficient (SCID) mice (C.B-17 background) were purchased from CLEA Japan, Inc. (Tokyo, Japan) and maintained at the National Cancer Center Research Institute East (Chiba, Japan). All animals were maintained under specific-pathogenfree, temperature-controlled environmental conditions throughout this study, in accordance with the Institutional Guidelines. Written approval for all animal experiments (K03-011) was obtained from the local Animal Experiments Committee of the National Cancer Center Research Institute.

Cell lines and cell cultures. KM104 cells, SV-40 transformed human fibroblast cell line derived from bone marrow, were originally established from male patient as described previously (27). This cell line was cultured in RPMI-1640 medium (Sigma) with $10 \%$ heat-inactivated fetal bovine serum (FBS) and antibiotics (penicillin and streptomycin). Human pancreatic cancer cell line Capan-1 was purchased from the American Type Culture Collection (Rockville, MD). The Capan-1 cells were maintained in DMEM (Sigma) medium with $20 \%$ heatinactivated FBS and antibiotics. All cells were maintained in a $5 \% \mathrm{CO}_{2}$ incubator at $37^{\circ} \mathrm{C}$.

Green fluorescent protein (GFP) labeling and cell sorting. KM104 were transfected with pEGFP-C1 vector encoding EGFP (Clonetech, Palo Alto, CA) by using Lipofectamine 2000 transfection reagent (Invitrogen, Carlsbad, CA). GFPpositive KM104 (KM104 ${ }^{\mathrm{GFP}}$ ) cells were sorted by using a FACSCalibur sorting system (Becton-Dickinson, San Jose, CA). After confirming that over $90 \%$ of cell line was GFP positive, they were used in the following experiment.

Intraperitoneal xenotransplantation of Capan-1 and KM104GFP. Capan- 1 cells $\left(5 \times 10^{6}\right.$ cells per animal) were injected into the peritoneal cavity of SCID mice as described previously, and $1 \mathrm{~h}$ later, $5 \times 10^{6} \mathrm{KM} 104^{\mathrm{GFP}}$ were injected into each peritoneal cavity at a different injection site (28). The animals were sacrificed on day 21 , and parapancreatic tumors were removed, minced, and cultured in 10\% FBS RPMI-1640. Under subconfluent conditions, the adherent cells were harvested, and the GFP-positive cells were sorted with the FACSCalibur sorting system.

Co-culture system. KM104GFP $\left(1 \times 10^{6}\right)$ and Capan- $1\left(2 \times 10^{5}\right)$ were co-cultured in RPMI-1640 medium with 10\% FBS. After 48 h, cells were collected, and GFP-positive cells were sorted with the cell sorter, and the cultured. KM104 ${ }^{\mathrm{GFP}}$ used in experiments were passaged by harvesting and distribution into five new plates. To obtain cell-conditioned medium, Capan-1 were cultured until semiconfluent conditions. The plate was then washed with sterile PBS, and the medium was changed to RPMI-1640+10\% FBS. After incubation for $24 \mathrm{~h}$, the Capan-1 culture supernatant was collected and added to the pre-seed KM104 ${ }^{\mathrm{GFP}}$, and their chemotactic activity was assayed $48 \mathrm{~h}$ later.

Migration assays. In the preliminary study, we tested the ability of 10 synthetic chemoattractants and growth factors (b-FGF, CCL-21, EGF, IGF-1, IL-8, PDGF-AA, PDGF-BB, SDF-1, TGF- $\beta$, VEGF-A), and found that PDGF-BB was the most powerful chemoattractant at the same protein concentrations (data not shown). PDGF-BB was therefore used as the chemoattractant in the subsequent experiments. The migration assay was performed by using 24-well culture chambers (Becton-Dickinson Labware, Bedford, MA) and a polycarbonate filter with an $8 \mu \mathrm{m}$ pore size (BectonDickinson Labware) as previously described (28). Briefly, the lower chamber contained $0.6 \mathrm{ml}$ of RPMI-1640 + recombinant PDGF-BB (final concentration; 0-100 ng/ml), or $0.6 \mathrm{ml}$ of RPMI-1640 as a control. In the upper compartment, $2 \times 10^{4}$ cells/well were placed in triplicate wells and incubated for $6 \mathrm{~h}$ at $37^{\circ} \mathrm{C}$ in a humidified incubator under a $5 \% \mathrm{CO}_{2}$ atmosphere. At the end of the incubation period, the cells that had passed through the filter into the lower wells were stained with hematoxylin, and the cells in nine predetermined fields were counted under a microscope.

Western blotting. Western blot analysis was performed as follows. Cells were lysed in whole-cell extraction buffer 
Case 1 Case 2

Case 3
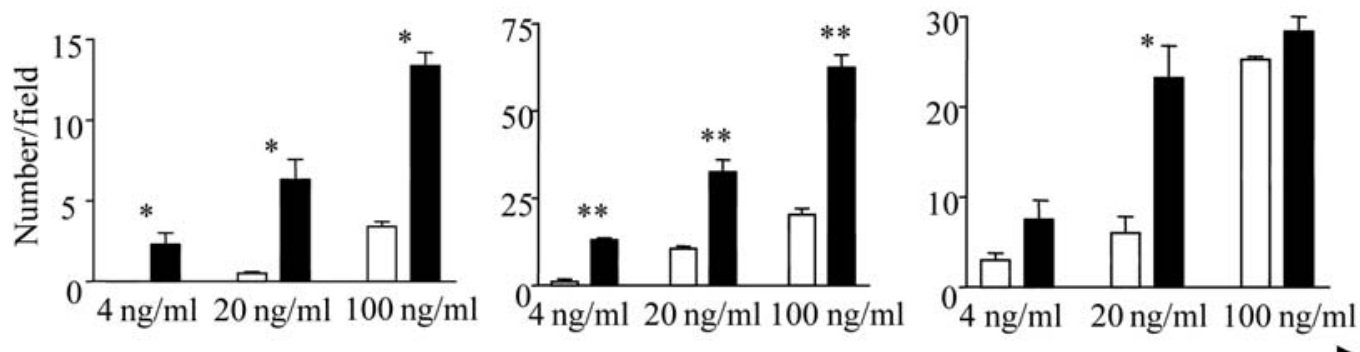

PDGF-BB

Case 4

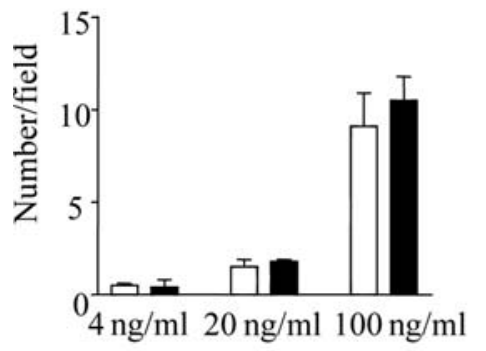

Case 5

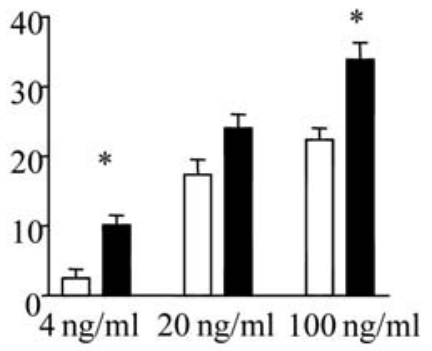

Case 6

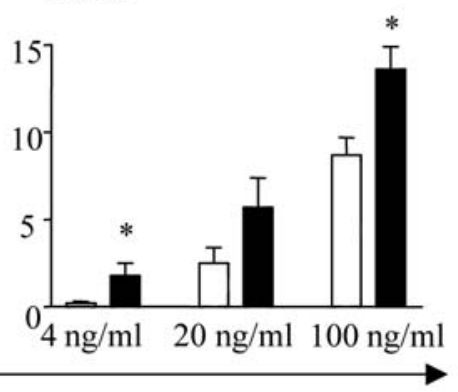

PDGF-BB

Figure 1. Cancer-associated fibroblasts (CAFs) isolated from human cancer tissue displayed enhanced migration activity in response to PDGF-BB. Fibroblasts isolated from human lung cancer tissue (cancer-associated fibroblasts; CAFs) and fibroblasts from corresponding non-cancerous lung tissues (non-canceroustissue-associated fibroblasts; NCAFs) were isolated and cultured, and their migration activity was compared. Except for case 4, migration activity of the CAFs in response to PDGF-BB was significantly higher than that of the NCAFs. $\left({ }^{*} \mathrm{P}<0.05,{ }^{* *} \mathrm{P}<0.01\right)$.

A

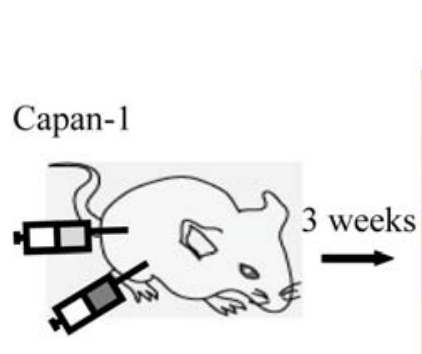

$\mathrm{KM} 104^{\mathrm{GFP}}$
B

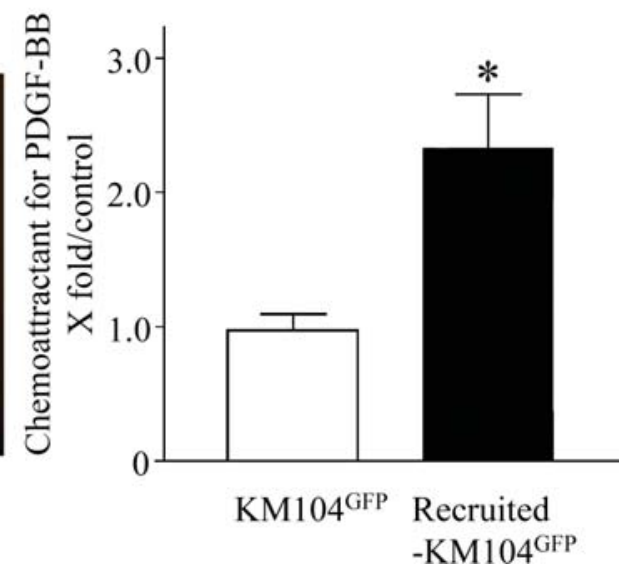

Figure 2. KM104 ${ }^{\mathrm{GFP}}$ recruited into cancer stroma in vivo display enhanced migration activity in response to PDGF-BB. (A) GFP-positive cells (KM104GFP) are scattered within this abdominal tumor. (B) GFP (+) cells were sorted from the minced abdominal tumor and cultured in vitro (rec-KM104 ${ }^{\mathrm{GFP}}$ ). Their migration activity in response to PDGF-BB was then compared with that of the parent cells (KM104 ${ }^{\mathrm{GFP}}$ ). Rec-KM104 ${ }^{\mathrm{GFP}}$ exhibited a 2.4 -fold higher migration activity than parent $\mathrm{KM} 104^{\mathrm{GFP}}\left(\mathrm{n}=3,{ }^{*} \mathrm{P}=0.03\right)$.

(20 mM Hepes-NaOH, 0.5\% NP-40, $15 \%$ glycerol) containing a Complete protease inhibitor cocktail tablet (Roche Diagnostics, Mannheim, Germany). Proteins were separated on $12 \%$ SDS-polyacrylamide gels and then transferred to an Immobilon-P PVDF (polyvinylidene fluoride) membrane (Millipore, Billerica, MA). The blots were saturated with blocking buffer (5\% skim milk in TBS-T) for $1 \mathrm{~h}$ at room temperature and then incubated for $1 \mathrm{~h}$ at $4^{\circ} \mathrm{C}$ with antiphospho-ERK1/2 antibody (mouse monoclonal IgG, E10, phospho-p44/42 MAPK antibody-Thr 202/Tyr 204) and total ERK1/2 antibody (rabbit polyclonal, p44/42 MAPK antibody) according to the manufacturer's instructions (Cell Signaling Technology, Beverly, MA, USA). After washing in TBS-T, the membranes were incubated for $1 \mathrm{~h}$ at room 


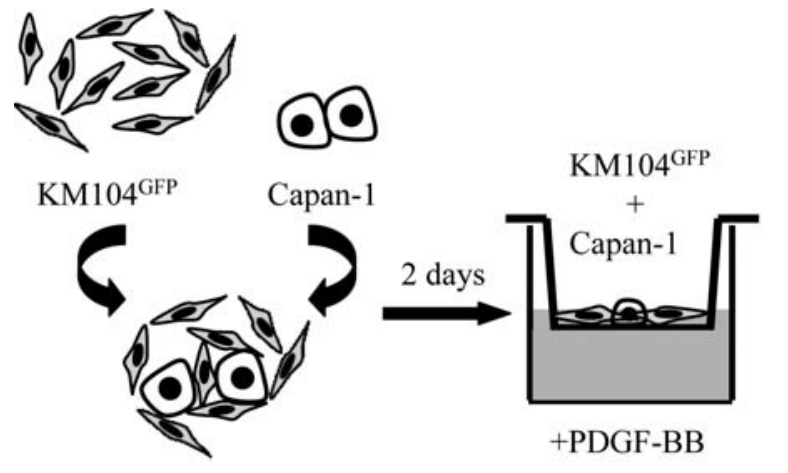

$\mathrm{KM} 104^{\mathrm{GFP}}+$ Capan-1

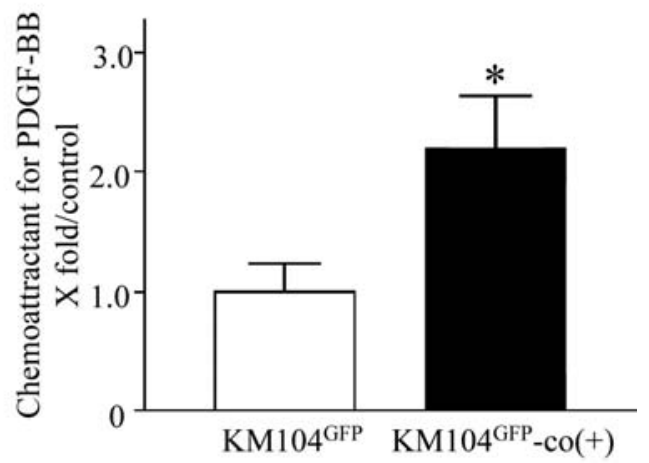

Figure 3. KM104GFP co-cultured with a cancer cell line display enhanced migration activity in response to PDGF-BB. KM104GFP were co-cultured with Capan-1 cells for two days [KM104 ${ }^{\mathrm{GFP}}-\mathrm{co}(+)$ ], and their migration activity in response to PDGF-BB was assayed. KM104 ${ }^{\mathrm{GFP}}-{ }_{-}$(o) displayed 2.2 -fold higher migration activity than KM104 ${ }^{\text {GFP }}$ cultured in the absence of Capan- $1\left(n=9,{ }^{*} \mathrm{P}=0.04\right)$

temperature with HRP-Rabbit anti-mouse IgG or HRP-goat anti-rabbit IgG (Zymed, San Francisco, CA). Antibody binding was detected with an Amersham enhanced chemiluminescence system.

Methylated DNA immunoprecipitation-chip (MeDIP-chip) assay. A $5 \mu \mathrm{g}$ sample of genomic DNA was sonicated to fragment lengths between 200 and $800 \mathrm{bp}$. After heat denaturation, the DNA was incubated with $5 \mu \mathrm{g}$ of antibody against 5-methyl cytidine (Diagnode, Liège, Belgium) at $4^{\circ} \mathrm{C}$ overnight. Immuno-complexes were collected with Dynabeads Protein A (Invitrogen Dynal AS, Oslo, Norway), treated with Proteinase K, and purified by phenol and chloroform extraction and isopropanol precipitation. The chip assay was carried out with a human CGI oligonucleotide microarray (Agilent Technologies, Santa Clara, CA). Immunoprecipitated DNA from $4.5 \mu \mathrm{g}$ of sonicated DNA and $1 \mu \mathrm{g}$ of input DNA were labeled with Cy-5 and Cy-3, respectively, using an Agilent labeling kit (Agilent Technologies), and then hybridized with the microarray. The microarray was scanned with an Agilent G2565BA microarray scanner (Agilent Technologies). The methylation statuses of 8,528 promoter CGIs were evaluated by using Me values, which have been shown to have a higher correlation coefficient with the fraction of methylated DNA molecules $(29,30)$, the methylation status of 8,528 promoter CGIs was evaluated.

$M E K$ inhibitor treatment. Cells were pretreated with the MEK1/2 inhibitor compound UO126 (Promega, San Diego, CA) or with DMSO vehicle alone before harvesting. UO126 was used at a concentration of $25 \mu \mathrm{M}$, which was shown to maximally inhibit MEK in fibroblasts. In the upper compartment, $2 \times 10^{4}$ cells/well were placed in medium containing $25 \mu \mathrm{M}$ of $\mathrm{U} 0126$ and incubated for $6 \mathrm{~h}$.

Statistical analyses. Three or four independent experiments were performed for each protocol. Results were expressed as the mean \pm standard error of the mean (SEM). Statistical calculations were performed by using Prism 3.03 software. Differences in measured variables between experimental groups and control groups were assessed by using an unpaired t-test. $\mathrm{P}<0.05$ was considered statistically significant.

\section{Results}

Cancer-associated fibroblasts (CAFs) isolated from human cancer tissue displayed enhanced migration activity in response to $P D G F-B B$. Fibroblasts isolated from human lung cancer tissue (cancer-associated fibroblasts; CAFs) and fibroblasts from corresponding non-cancerous lung tissues (noncancerous tissue-associated fibroblasts; NCAFs) were isolated and cultured, and their migration activity was compared. Except for Case 4, migration activity of the CAFs in response to PDGF-BB was significantly higher than that of the NCAFs (Fig. 1).

Fibroblast cell line KM104 ${ }^{G F P}$ recruited into cancer stroma displays enhanced migration activity in response to $P D G F-B B$. Capan-1 and KM104 ${ }^{\mathrm{GFP}}$ were injected intraperitoneally at a different site. Immunofluorescence examination of the parapancreatic tumor revealed the presence of KM104GFP within the cancer tissue (Fig. 2A). GFP (+) cells were sorted from the minced parapancreatic tumor and cultured, and the chemoattractant response of the KM104 ${ }^{\mathrm{GFP}}$ to PDGF-BB was compared with that of the parent cells. KM104 ${ }^{\mathrm{GFP}}$ recruited into the tumor exhibited a 2.4-fold higher migration activity than parent $\mathrm{KM}_{104^{\mathrm{GFP}}}$ (n=3, Fig. 2B, P=0.03).

KM104 ${ }^{G F P}$ co-cultured with the cancer cell line displayed enhanced migration activity in response to PDGF-BB. We co-cultured KM104 ${ }^{\mathrm{GFP}}$ and Capan-1 for two days and assayed the migration activity of KM104 ${ }^{\mathrm{GFP}}$ in response to PDGF-BB. No Capan-1 cells were able to migrate through the cell culture insert $(8.0 \mu \mathrm{m}$ pore size) under these conditions. KM104 ${ }^{\mathrm{GFP}}$ co-cultured with Capan-1 [KM104GFP-co(+)] displayed 2.2-fold higher migration activity than KM104GFP cultured in the absence of Capan-1 ( $\mathrm{n}=9, \mathrm{P}=0.04$, Fig. 3).

Cell-cell contact is necessary for enhanced migration activity. To explore whether cell-cell contact is necessary for KM104 GFP to exhibit enhanced migration activity, we cultured KM104GFP with KM104 cell conditioned medium (control) or Capan-1 cell conditioned medium for 2 days, and assayed their migration activity, but no significant difference in migration activity was found between the two groups (Fig. 4A). Next, 
A

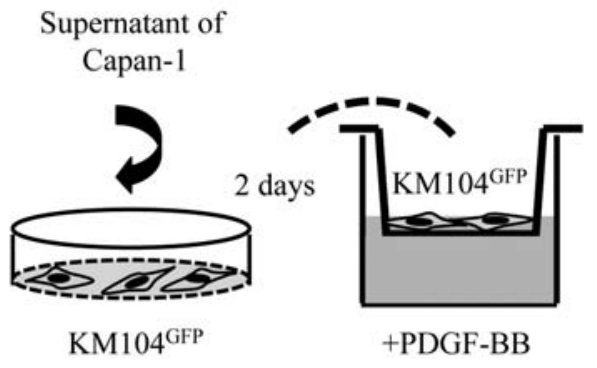

B

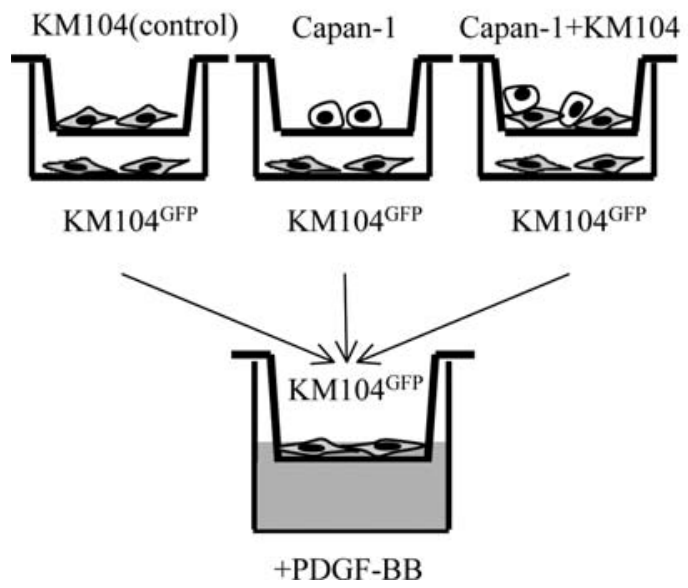

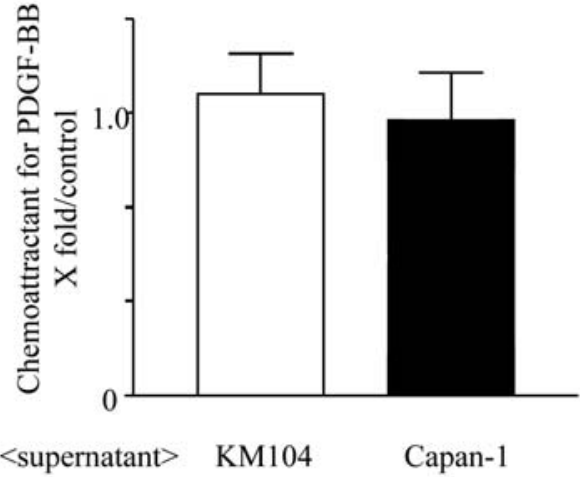

$<$ supernatant $>$ KM104 Capan-1

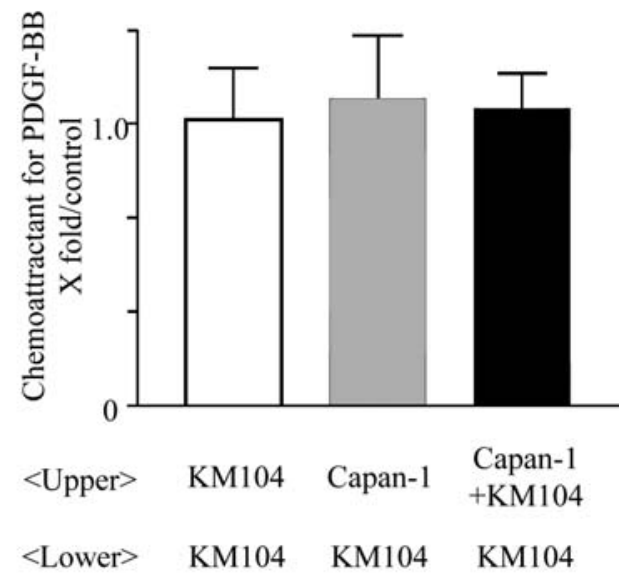

Figure 4. Cell-cell contact is necessary for enhanced migration activity. (A) KM104GFP cells were cultured with conditioned medium from KM104 cell cultures (control) or Capan-1 cell cultures for 2 days, and their migration activity was assayed. (B) KM104 ${ }^{\text {GFP }}$ were co-cultured in the 2-chamber system (upper chamber; KM104, Capan-1, or Capan-1 +KM104, lower chamber; KM104GFP) for 2 days, and the migration activity of the KM104GFP cultured in the lower chamber was assayed.

KM104 ${ }^{\mathrm{GFP}}$ were co-cultured in the 2-chamber system (upper chamber: KM104, Capan-1, or Capan-1+KM104; lower chamber: KM104 ${ }^{\mathrm{GFP}}$ ) for 2 days, and the migration activity of the KM104 ${ }^{\mathrm{GFP}}$ cultured in lower chamber was assayed (Fig. 4B). Migration number of KM104 ${ }^{\mathrm{GFP}}$ exposed to Capan-1 cell supernatant (middle column) and KM104 ${ }^{\mathrm{GFP}}$ exposed to Capan-1+KM104 cells supernatant (right column) was almost the same as that of control group (left column). These findings suggested that direct KM104-Capan-1 contact is necessary for KM104 ${ }^{\mathrm{GFP}}$ to exhibit enhanced migration activity.

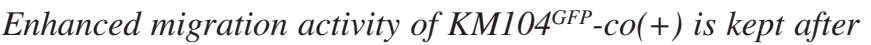
separation from cancer cells. GFP-positive KM104 were sorted $\left(3.0 \times 10^{5}\right)$ from cocultured Capan-1 and cultured (Fig. $5 \mathrm{~A})$. In a control experiment, KM104 ${ }^{\mathrm{GFP}}$ alone were cultured, and GFP-positive cells were sorted (sham-sorted) and cultured. Cells from subconfluent cultures $\left(1.0 \times 10^{6}\right)$ were then assayed for migration activity in response to PDGF-BB. The results showed that the sorted KM104 ${ }^{\mathrm{GFP}}-\mathrm{co}(+)$ displayed 2.3-fold higher activity than sham-sorted KM104 ${ }^{\mathrm{GFP}}(\mathrm{P}=0.02)$, indicating that the sorted $\mathrm{KM} 104^{\mathrm{GFP}}-\mathrm{Co}(+)$ displayed enhanced migration activity for almost 2 popu-lation doublings after separation from the cancer cells.
Sorted KM104 ${ }^{\mathrm{GHP}}$-co(+) were then serially passaged by harvesting and distribution into five new plates, and migration activity was compared in each passage culture. Three independent experiments were performed, and the results are shown in Fig. 5B. The sorted KM104 ${ }^{\mathrm{GFP}}-\mathrm{CO}(+)$ kept their enhanced migration activity even after the passage- 5 culture in every experiment. In experiments 2 and 3, the enhanced migration activity of the sorted $\mathrm{KM} 104^{\mathrm{GFP}}-\mathrm{CO}(+)$ returned to the levels of passaged sham-sorted KM104 ${ }^{\mathrm{GFP}}$ cells in the passage- 6 culture. These results indicate that the sorted KM104 GFP $\mathrm{co}(+)$ retained the enhanced migration activity for at least 13 population doublings after separation from the cancer cells in vitro.

MeDIP-chip analysis of CAFs. Because of the prolonged enhanced migration activity of CAFs, it was important to analyze the epigenetic changes that accompany this phenomenon. We used a methylation screening approach called MeDIP-chip to compare the DNA methylation profiles of the CAFs and corresponding NCAFs from two cases. The results of the MeDIP-chip analysis showed that 2.2\% (188 promoter CGIs) (Case 1) and $1.1 \%$ (98 promoter CGIs) (Case 2) of the CGIs were hypermethylated in CAFs compared with NCAFs. 
$\mathbf{A}$
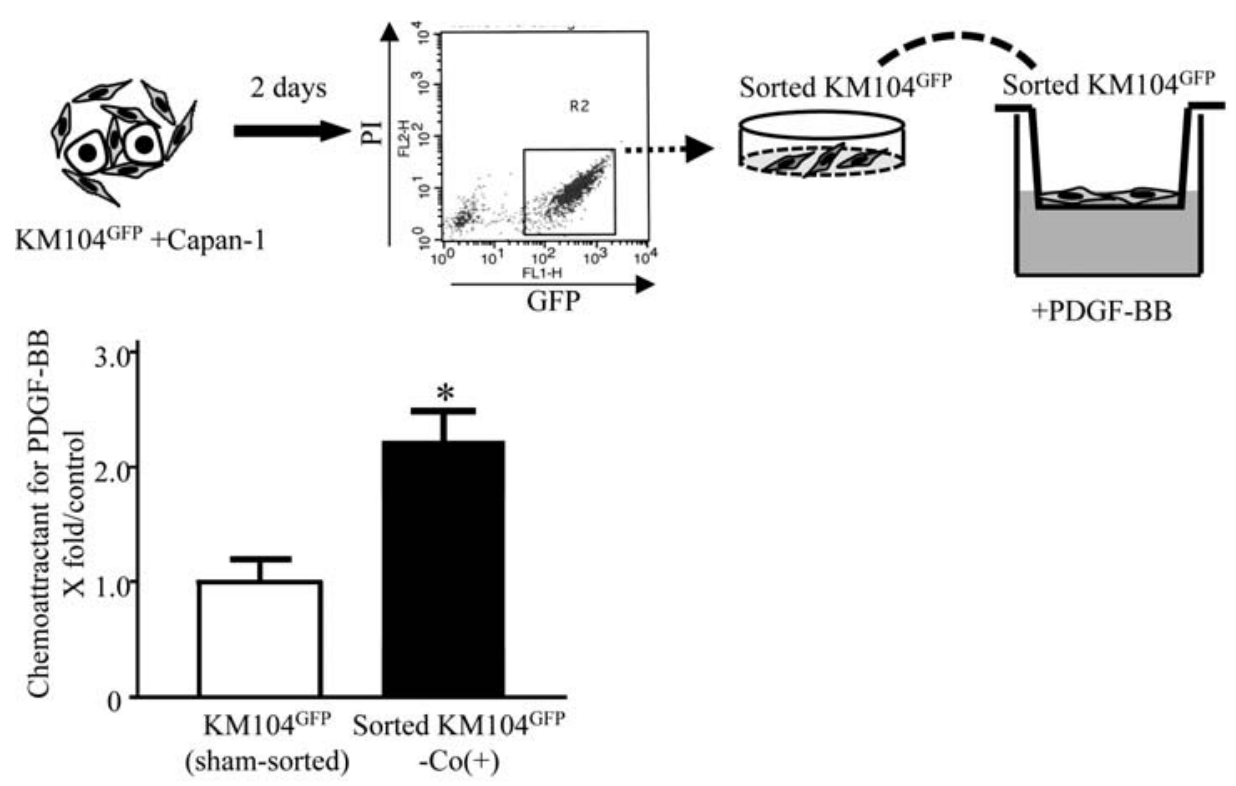

B
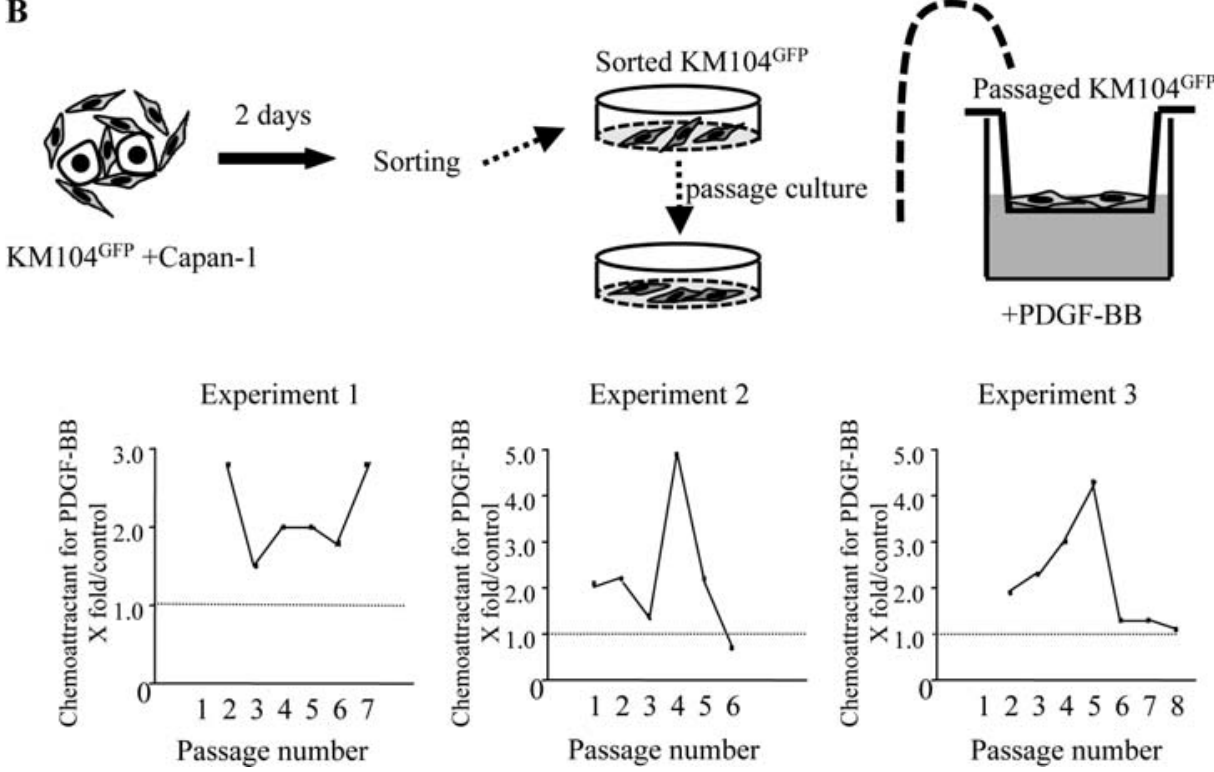

Figure 5. Sustained enhanced migration activity of $\mathrm{KM} 104^{\mathrm{GFP}}-\mathrm{co}(+)$ after separation from the cancer cells. (A) After sorting from the co-cultured Capan-1, GFP-positive KM104 were sorted and cultured [Sorted KM104 ${ }^{\text {GFP }}$-co(+)]. In a control experiment, KM104 ${ }^{\text {GFP }}$ alone were cultured, and the GFP-positive cells were sorted (sham-sorted) and cultured. Cells from a subconfluent culture were then examined for migration activity in response to PDGF-BB. Sorted $\mathrm{KM} 104^{\mathrm{GFP}}-\mathrm{co}(+)$ displayed 2.3-fold higher activity than sham-sorted KM104 ${ }^{\mathrm{GFP}}\left(\mathrm{n}=3,{ }^{*} \mathrm{P}=0.02\right)$. (B) Sorted KM104 ${ }^{\mathrm{GFP}}$-co $(+)$ were serially passaged by harvesting and distribution into five new plates, and their migration activity was compared at each passage culture. Representative data of three independent experiments are shown.

$0.5 \%$ (39 promoter CGIs) (Case 1) and $0.6 \%$ (50 promoter CGIs) (Case 2) were hypomethylated in CAFs compared with NCAFs (Table I). Ten promoter CGIs (ALDH1L2, AP1G2, CENPJ, KBTBD6, MAB21L1, MED4, RCBTB2, SH2B3, $T B C 1 D 4$ and $U B L 3$ ) were hypermethylated in the CAFs from both cases (Table II), but no promoter CGIs were hypomethylated in the CAFs from either of the cases.

Role of extracellular signal-regulated kinase (ERK) $1 / 2$ in PDGF-BB-induced migration of sorted $\mathrm{KMIO4}^{\mathrm{GFP}}-\mathrm{co}(+)$ and $C A F s$. Activation of extracellular signal-regulated kinase (ERK) 1/2 has been reported to play crucial role in PDGFinduced cell migration. We analyzed the effects of PDGF-BB
Table I. Aberrantly methylated promoter CGIs in CAF to be compared with NCAF.

Pair No. of genes

Hypermethylated genes

Case $1 \quad 188$

Case $2 \quad 98$

Hypomethylated genes

$\begin{array}{ll}\text { Case } 1 & 39 \\ \text { Case } 2 & 50\end{array}$


A

\begin{tabular}{|c|c|c|c|c|c|}
\hline & $\begin{array}{l}\text { Sham-sorted } \\
\text { KM104 }\end{array}$ & $\begin{array}{c}\text { Sorted } \\
\text { KM104 } 4^{\mathrm{GFP}_{-}} \mathrm{co}(+)\end{array}$ & & NCAF & $\mathrm{CAF}$ \\
\hline & $0 \mathrm{~m} 5 \mathrm{~m} \mathrm{10m} \mathrm{1h} 3 \mathrm{~h}$ & $0 \mathrm{~m} 5 \mathrm{~m} \mathrm{10m} \mathrm{1h} 3 \mathrm{~h}$ & & $0 \mathrm{~m} 5 \mathrm{~m} \mathrm{10m} \mathrm{1h} 3 \mathrm{~h}$ & $0 \mathrm{~m} 5 \mathrm{~m} 10 \mathrm{~m} \mathrm{lh} 3 \mathrm{~h}$ \\
\hline p-ERK $1 / 2$ & & & p-ERK $1 / 2$ & E=ニニ & $=5= \pm=$ \\
\hline
\end{tabular}

\section{B}
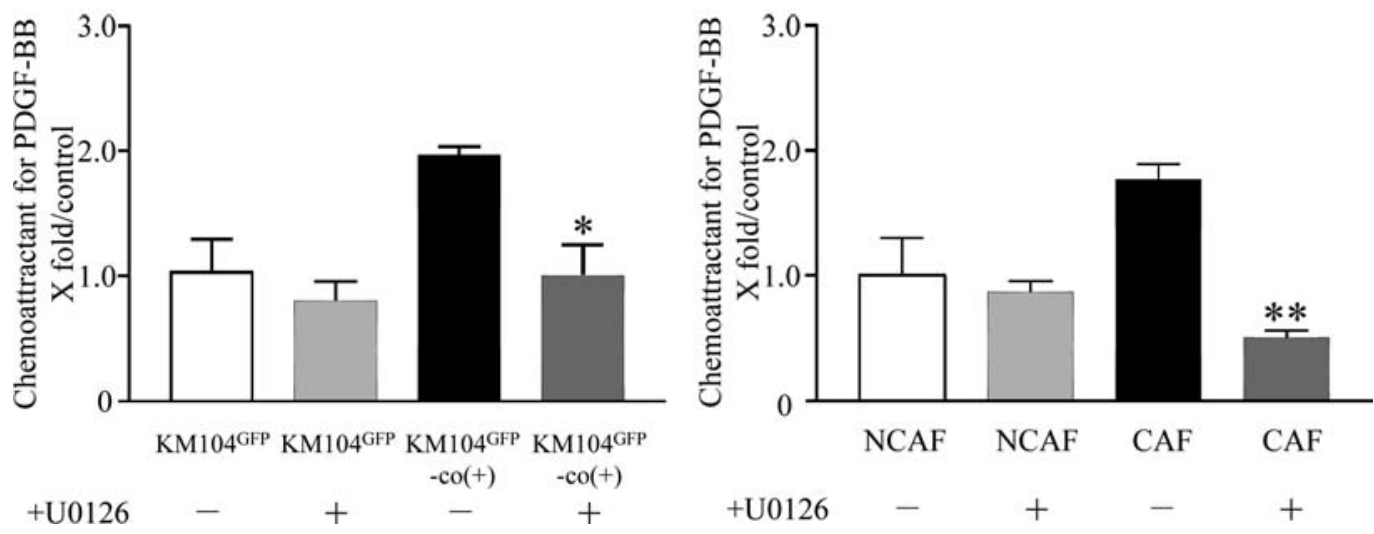

Figure 6. Role of extracellular signal-regulated kinase (ERK) 1/2 in PDGF-BB-induced migration by sorted KM104 ${ }^{\text {GFP }}$-co(+) cells and CAFs. (A) Western blotting of phosphorylated ERK1/2. PDGF-BB increased the level of ERK1/2 phosphorylation in sham-sorted KM104 ${ }^{\text {GFP }}$ cells, sorted KM104 ${ }^{\text {GFP }}$-co(+) cells, NCAFs, and CAFs in a time-dependent manner, reaching a maximum at 300-600 sec, and the phosphorylation level decreased slightly thereafter. (B) Inhibitory effect of treatment with UO126 $(25 \mu \mathrm{M})$ on cell migration. Treatment of the sham-sorted KM104 ${ }^{\mathrm{GFP}}$ and KM104 ${ }^{\mathrm{GFP}}-\mathrm{co}(+)$ with UO126 decreased migration to $80.0 \pm 15.3 \%$ and $50.1 \pm 10.8 \%$ of untreated group, respectively $(\mathrm{P}=0.01)$. UO126 decreased the migration of NCAFs and $\mathrm{CAFs}$ to $86.7 \pm 8.9 \%$ and $28.1 \pm 1.6 \%$ of untreated group, respectively $(\mathrm{P}=0.001)$.

Table II. Genes hypermethylated in both CAFs.

\begin{tabular}{ll}
\hline Gene ID & \multicolumn{1}{c}{ Gene name } \\
\hline 160428 & Aldehyde dehydrogenase 1 family, member L2 (ALDH1L2) \\
8906 & Adaptor-related protein complex 1, $\gamma$ 2 subunit (AP1G2) \\
55835 & Centromere protein J (CENPJ) \\
89890 & Kelch repeat and BTB (POZ) domain containing 6 (KBTBD6) \\
4081 & Mab-21-like 1 (C. elegans) (MAB21L1) \\
29079 & Mediator complex subunit 4 (MED4) \\
1102 & Regulator of chromosome condensation and BTB domain containing protein 2 (RCBTB2) \\
10019 & SH2B adaptor protein 3 (SH2B3) \\
9882 & TBC1 domain family, member 4 (TBC1D4) \\
5412 & Ubiquitin-like 3 (UBL3)
\end{tabular}

Hypomethylated genes in both CAFs were not found.

on ERK1/2 activation of sorted KM104 ${ }^{\mathrm{GFP}}-\mathrm{co}(+)$. As shown in Fig. 6A, PDGF-BB increased ERK1/2 phosphorylation in both sham-sorted KM104 ${ }^{\mathrm{GFP}}$ and sorted $\mathrm{KM} 104^{\mathrm{GFP}}-\mathrm{CO}(+)$ in a time-dependent manner up to a maximum at 300-600 sec, and the phosphorylation level decreased thereafter. The levels of phosphorylated ERK1/2 in both sham-sorted KM104 ${ }^{\mathrm{GFP}}$ and sorted KM104 ${ }^{\mathrm{GFP}}-\mathrm{co}(+)$ was similar, and this phenomenon was also observed in CAFs and NCAFs isolated from lung cancer tissue.

Treatment of the sham-sorted KM104GFP with UO126 $(25 \mu \mathrm{M})$, a highly selective inhibitor of both MEK1 and MEK2, decreased migration to only $80.0 \pm 15.3 \%$ of untreated group, whereas it decreased migration of the sorted KM104 GFP $\mathrm{co}(+)$ to $50.1 \pm 10.8 \%$ of untreated group $(\mathrm{P}=0.01)$ (Fig. $6 \mathrm{~B})$. 
Furthermore, although U0126 decreased the PDGF-BBinduced migration of NCAFs to only $86.7 \pm 8.9 \%$ of untreated group, it decreased the migration of CAFs to $28.1 \pm 1.6 \%$ of untreated group $(\mathrm{P}=0.001)$.

\section{Discussion}

In the current study we demonstrated that fibroblasts that have associated with cancer cells retain their enhanced migration activity for a while after separation from the cancer cells. Furthermore, we first report the possibility that one of the biological characteristics of CAFs would be higher dependence on ERK1/2 signaling for their enhanced migration activity even in the absence of cancer cells.

It is now clear that activation of ERK $1 / 2$ is important for PDGF-induced cell migration (31-33). We examined the levels of ERK1/2 phosphorylation of sorted-KM104 ${ }^{\mathrm{GFP}}-\mathrm{CO}(+)$ and CAFs after PDGF-BB treatment, but there was no significant difference from the level in the control cells. However, the inhibitory effect of a selective inhibitor of both MEK1 and MEK2 on migration was significantly higher in sortedKM104 ${ }^{\mathrm{GFP}}-\mathrm{co}(+)$ and CAFs than in control cells. We also investigated the involvement of other MAPK family, including the JNK and P38, however, phosphorylation of these molecules in sorted-KM104 ${ }^{\mathrm{GFP}}$-co(+)and CAFs were almost the similar level as those of control cells with or without PDGFBB stimulation. Moreover, the inhibitory effect of their specific inhibitor SP600125 or SB203580 on cell migration in sorted-KM104 ${ }^{\mathrm{GFP}}-\mathrm{CO}(+)$ and $\mathrm{CAFs}$ and in untreated cells was almost equal (data not shown). This finding indicated that the fibroblasts that had associated with cancer cells were more dependent on the ERK1/2 pathway for cell migration. Activated ERKs regulate membrane protrusions and focal adhesion dynamics via myosin light chain kinase (MLCK), calpain, paxillin, and focal adhesion kinase (FAK) activation (32), however, the MeDIP-chip analysis did not reveal any promoter CGIs involved in these molecules. After association with cancer cells, pairs of factors that have a synthetic relationship in CAFs may differ from those in naive fibroblasts, thus increasing the dependence of cells on the downstream ERK1/2 pathway. Alternatively, the downstream ERK1/2 signaling pathway may play a more essential and qualitatively different role in a given pathway in CAFs than in naive fibroblasts, making them much more dependent on the activity of a specific signaling pathway. The direct association with cancer cells may cause 'signaling addiction' to occur in fibroblasts, which would be a similar condition explained by the concept of 'oncogene addiction' that some cancer cells are dependent on or addicted to one or a few genes for both maintenance of their malignant phenotype and cell survival $(34,35)$.

DNA methylation is one of the molecular mechanisms that have long-term effects on gene expression. Since the enhanced migration activity of fibroblasts continues after being separated from cancer cells, we speculated that the association with cancer cells might change the methylation status of certain DNA(s) involved in cell migration. MeDIPchip analysis identified that 10 promoter CGIs ( $A L D H 1 L 2$, AP1G2, CENPJ, KBTBD6, MAB21L1, MED4, RCBTB2, $S H 2 B 3, T B C 1 D 4$ and $U B L 3$ ) that were hypermethylated, no promoter CGIs were hypomethylated in both CAFs, and we were unable to identify any well-known methylated genes that were directly involved in cell migration. The cause of the persistent enhanced migration activity remains unknown, and additional research on chromatin modifications, such as histone deacetylation, will be necessary to understand the mechanisms underlying this phenomenon in CAFs.

Jiang et al detected global hypomethylation of genomic DNA by means of a methylation-sensitive SNP array analysis (MSNP), a restriction enzyme-based analysis, in the stromal myofibroblasts of gastric carcinomas (36). By contrast, when we focused on promoter CGIs in the current study, the results showed a higher number of hypermethylated genes than hypomethylated genes in CAFs (hypermethylated: 188 CGIs in Case 1 and 98 CGIs in Case 2; hypomethylated: 39 CGIs in Case 1 and 50 CGIs in Case 2). This difference might be caused by CGIs to be focused on. Our data showed for the first time that a few hundred genes were aberrantly hypermethylated in CAFs, suggesting that some regulators can be epigenetically targeted by the cancer microenvironment $(37,38)$.

Cultured fibroblasts from idiopathic pulmonary fibrosis (IPF) were found to migrate faster than those from control fibroblasts, indicating that they also retained enhanced migration activity in vitro (39). Since there are many parallels between cancer and chronic active inflammation, as described in the saying, 'tumours are wounds that never heal', enhanced migration may be a common characteristic of fibroblasts recruited into fibrotic lesions.

Our current results may imply that by using this special property of CAFs, strategies that are directed to block the recruitment and tumor-associated functions of CAFs could be a possible method against tumors. Although the exact mechanisms of this phenomenon are not fully understood, cellular and molecular studies on the role of 'educated fibroblasts' should provide novel insights into the pathogenesis of a unique microenvironment of cancers.

\section{Acknowledgements}

This study was supported in part by the Grant-in-Aid for Cancer Research (19-10) from the Ministry of Health, Labour and Welfare, the Grant for Scientific Research Expenses for Health Labour and Welfare Programs, the Foundation for the Promotion of Cancer Research, 3rd-Term Comprehensive 10-year Strategy for Cancer Control, and Special Coordination Funds for Promoting Science and Technology from the Ministry of Education, Culture, Sports, Science and Technology, the Japanese Government.

\section{References}

1. Lin EY, Nguyen AV, Russell RG and Pollard JW: Colonystimulating factor 1 promotes progression of mammary tumors to malignancy. J Exp Med 193: 727-740, 2001.

2. Hartel M, Di Mola FF, Gardini A, Zimmermann A, Di Sebastiano P, Guweidhi A, Innocenti P, Giese T, Giese N, Büchler MW and Friess H: Desmoplastic reaction influences pancreatic cancer growth behavior. World J Surg 28: 818-825, 2004.

3. Iwano M, Plieth D, Danoff TM, Xue C, Okada H and Neilson EG: Evidence that fibroblasts derive from epithelium during tissue fibrosis. J Clin Invest 110: 341-350, 2002. 
4. Ishii G, Sangai T, Oda T, Aoyagi Y, Hasebe T, Kanomata N, Endoh Y, Okumura C, Okuhara Y, Magae J, Emura M, Ochiya T and Ochiai A: Bone-marrow-derived myofibroblasts contribute to the cancer-induced stromal reaction. Biochem Biophys Res Commun 309: 232-240, 2003.

5. Wels J, Kaplan RN, Rafii S and Lyden D: Migratory neighbors and distant invaders: tumor-associated niche cells. Genes Dev 22: 559-574, 2008.

6. Sangai T, Ishii G, Kodama K, Miyamoto S, Aoyagi Y, Ito T, Magae J, Sasaki H, Nagashima T, Miyazaki M and Ochiai A: Effect of differences in cancer cells and tumor growth sites on recruiting bone marrow-derived endothelial cells and myofibroblasts in cancer-induced stroma. Int J Cancer 115: 885-892, 2005.

7. Chiba H, Ishii G, Ito TK, Aoyagi K, Sasaki H, Nagai K and Ochiai A: CD105-positive cells in pulmonary arterial blood of adult human lung cancer patients include mesenchymal progenitors. Stem Cells 26: 2523-2530, 2008.

8. Bissell MJ and Radisky D: Putting tumours in context. Nat Rev Cancer 1: 46-54, 2001

9. Hawsawi NM, Ghebeh H, Hendrayani SF, Tulbah A, Al-Eid M, Al-Tweigeri T, Ajarim D, Alaiya A, Dermime $S$ and Aboussekhra A: Breast carcinoma-associated fibroblasts and their counterparts display neoplastic-specific changes. Cancer Res 68: 2717-2725, 2008.

10. Okusa Y, Ichikura T and Mochizuki H: Prognostic impact of stromal cell-derived urokinase-type plasminogen activator in gastric carcinoma. Cancer 85: 1033-1038, 1999.

11. Tokunou M, Niki T, Eguchi K, Iba S, Tsuda H, Yamada T, Matsuno Y, Kondo H, Saitoh Y, Imamura $\mathrm{H}$ and Hirohashi S: cMET expression in myofibroblasts: role in autocrine activation and prognostic significance in lung adenocarcinoma. Am J Pathol 158: 1451-1463, 2001

12. Orimo A, Gupta PB, Sgroi DC, Arenzana-Seisdedos F, Delaunay T, Naeem R, Carey VJ, Richardson AL and Weinberg RA: Stromal fibroblasts present in invasive human breast carcinomas promote tumor growth and angiogenesis through elevated SDF-1/CXCL12 secretion. Cell 121: 335-348, 2005.

13. Karnoub AE, Dash AB, Vo AP, Sullivan A, Brooks MW, Bell GW, Richardson AL, Polyak K, Tubo R and Weinberg RA: Mesenchymal stem cells within tumour stroma promote breast cancer metastasis. Nature 449: 557-563, 2007

14. Coussens LM, Tinkle CL, Hanahan D and Werb Z: MMP-9 supplied by bone marrow-derived cells contributes to skin carcinogenesis. Cell 103: 481-490, 2000.

15. Ito TK, Ishii $\mathrm{G}$, Chiba $\mathrm{H}$ and Ochiai $\mathrm{A}$ : The VEGF angiogenic switch of fibroblasts is regulated by MMP-7 from cancer cells. Oncogene 26: 7194-7203, 2007.

16. Hasebe T, Sasaki S, Imoto S and Ochiai A: Proliferative activity of intratumoral fibroblasts is closely correlated with lymph node and distant organ metastases of invasive ductal carcinoma of the breast. Am J Pathol 156: 1701-1710, 2000.

17. Kawase A, Ishii G, Nagai K, Ito T, Nagano T, Murata Y, Hishida T, Nishimura M, Yoshida J, Suzuki K and Ochiai A: Podoplanin expression by cancer associated fibroblasts predicts poor prognosis of lung adenocarcinoma. Int J Cancer 123: 1053-1059, 2008.

18. Nakao M, Ishii G, Nagai K, Kawase A, Kenmotsu H, Kon-No H, Hishida T, Nishimura M, Yoshida J and Ochiai A: Prognostic significance of carbonic anhydrase IX expression by cancerassociated fibroblasts in lung adenocarcinoma. Cancer 115: 2732-2743, 2009.

19. Nakagawa H, Liyanarachchi S, Davuluri RV, Auer H, Martin EW Jr, de la Chapelle A and Frankel WL: Role of cancerassociated stromal fibroblasts in metastatic colon cancer to the liver and their expression profiles. Oncogene 23: 7366-7377, 2004.

20. Tuhkanen H, Anttila M, Kosma VM, Yla-Herttuala S, Heinonen S, Kuronen A, Juhola M, Tammi R, Tammi M and Mannermaa A: Genetic alterations in the peritumoral stromal cells of malignant and borderline epithelial ovarian tumors as indicated by allelic imbalance on chromosome 3p. Int J Cancer 109: 247252, 2004

21. Fukino K, Shen L, Matsumoto S, Morrison CD, Mutter GL and Eng C: Combined total genome loss of heterozygosity scan of breast cancer stroma and epithelium reveals multiplicity of stromal targets. Cancer Res 64: 7231-7236, 2004.
22. Weber F, Shen L, Fukino K, Patocs A, Mutter GL, Caldes T and Eng C: Total-genome analysis of BRCA1/2-related invasive carcinomas of the breast identifies tumor stroma as potential landscaper for neoplastic initiation. Am J Hum Genet 78: 961-972, 2006.

23. Qiu W, Hu M, Sridhar A, Opeskin K, Fox S, Shipitsin M, Trivett M, Thompson ER, Ramakrishna M, Gorringe KL, Polyak K, Haviv I and Campbell IG: No evidence of clonal somatic genetic alterations in cancer-associated fibroblasts from human breast and ovarian carcinomas. Nat Genet 40: 650-655, 2008.

24. Korc M: Pancreatic cancer-associated stroma production. Am J Surg 194 (Suppl. 4): S84-S86, 2007.

25. Grum-Schwensen B, Klingelhofer J, Berg CH, El-Naaman C, Grigorian M, Lukanidin E and Ambartsumian N: Suppression of tumor development and metastasis formation in mice lacking the S100A4(mts1) gene. Cancer Res 65: 3772-3780, 2005.

26. Hoshino A, Chiba H, Nagai K, Ishii G and Ochiai A: Human vascular adventitial fibroblasts contain mesenchymal stem/ progenitor cells. Biochem Biophys Res Commun 368: 305-310, 2008.

27. Harigaya $\mathrm{K}$ and Handa $\mathrm{H}$ : Generation of functional clonal cell lines from human bone marrow stroma. Proc Natl Acad Sci USA 82: 3477-3480, 1985

28. Ishii G, Sangai T, Ito T, Hasebe T, Endoh Y, Sasaki H, Harigaya $\mathrm{K}$ and Ochiai $\mathrm{A}$ : In vivo and in vitro characterization of human fibroblasts recruited selectively into human cancer stroma. Int J Cancer 117: 212-220, 2005.

29. Takeshima H, Yamashita S, Shimazu T, Niwa T and Ushijima T: The presence of RNA polymerase II, active or stalled, predicts epigenetic fate of promoter $\mathrm{CpG}$ islands. Genome Res 19: 1974-1982, 2009.

30. Yamashita S, Hosoya K, Gyobu K, Takeshima H and Ushijima T: Development of a novel output value for quantitative assessment in methylated DNA immunoprecipitation-CpG island microarray analysis. DNA Res 16: 275-286, 2009.

31. Lundberg MS, Curto KA, Bilato C, Monticone RE and Crow MT: Regulation of vascular smooth muscle migration by mitogenactivated protein kinase and calcium/calmodulin-dependent protein kinase II signaling pathways. J Mol Cell Cardiol 30: 2377-2389, 1998.

32. Huang C, Jacobson K and Schaller MD: MAP kinases and cell migration. J Cell Sci 117: 4619-4628, 2004.

33. Lee CK, Lee HM, Kim HJ, Park HJ, Won KJ, Roh HY, Choi WS, Jeon BH, Park TK and Kim B: Syk contributes to PDGF-BBmediated migration of rat aortic smooth muscle cells via MAPK pathways. Cardiovasc Res 74: 159-168, 2007.

34. Weinstein IB and Joe AK: Mechanisms of disease: Oncogene addiction-a rationale for molecular targeting in cancer therapy. Nat Clin Pract Oncol 3: 448-457, 2006.

35. Weinstein IB and Joe A: Oncogene addiction. Cancer Res 68: 3077-3080, 2008.

36. Jiang L, Gonda TA, Gamble MV, Salas M, Seshan V, Tu S, Twaddell WS, Hegyi P, Lazar G, Steele I, Varro A, Wang TC and Tycko B: Global hypomethylation of genomic DNA in cancer-associated myofibroblasts. Cancer Res 68: 9900-9908, 2008.

37. Fiegl H, Millinger S, Goebel G, Muller-Holzner E, Marth C, Laird PW and Widschwendter M: Breast cancer DNA methylation profiles in cancer cells and tumor stroma: association with HER-2/neu status in primary breast cancer. Cancer Res 66: 29-33, 2006.

38. Hanson JA, Gillespie JW, Grover A, Tangrea MA, Chuaqui RF, Emmert-Buck MR, Tangrea JA, Libutti SK, Linehan WM and Woodson KG: Gene promoter methylation in prostate tumorassociated stromal cells. J Natl Cancer Inst 98: 255-261, 2006.

39. Suganuma H, Sato A, Tamura R and Chida K: Enhanced migration of fibroblasts derived from lungs with fibrotic lesions. Thorax 50: 984-989, 1995. 